\title{
Time-resolved mass spectroscopic studies of an atmospheric-pressure helium
} microplasma jet

3

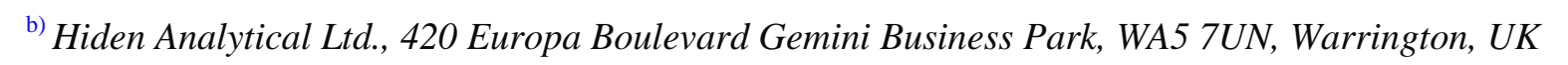

\author{
${ }^{c)}$ Author for correspondence: j.w.bradley@liv.ac.uk
}

\section{Abstract}

2 Using molecular beam mass spectroscopy, time-resolved measurements of the ionic species in the plasma plume of an atmospheric-pressure helium microplasma jet have been made for a range of excitation frequencies $(5,10$ and $25 \mathrm{kHz})$ and source-instruments orifice distances (1, 7 and $11 \mathrm{~mm})$. Ionic species can only be observed in the visible plasma plume, with the 6 main positive species being $\mathrm{N}_{2}^{+}(65.26 \%)$ and $\mathrm{O}_{2}{ }^{+}(21.11 \%)$, and few percentages of $\mathrm{N}^{+}, \mathrm{O}^{+}$, $7 \mathrm{NO}^{+}$and $\mathrm{He}^{+}$. For the negative ions, the majority species are $\mathrm{O}_{3}^{-}(22.68 \%), \mathrm{O}_{2}^{-}\left(\mathrm{H}_{2} \mathrm{O}\right)$ $8(10.49 \%)$ and a large range of minority species observed namely, $\mathrm{O}_{\mathrm{n}}^{-}, \mathrm{OH}_{\mathrm{n}}{ }^{-},\left(\mathrm{H}_{2} \mathrm{O}\right)_{\mathrm{n}}{ }^{-}, \mathrm{CO}_{\mathrm{n}}{ }^{-}$ 9 and clusters, $\mathrm{O}_{\mathrm{m}}{ }^{-}\left(\mathrm{H}_{2} \mathrm{O}\right)_{\mathrm{n}},(\mathrm{OH})_{\mathrm{m}}{ }^{-}\left(\mathrm{H}_{2} \mathrm{O}\right)_{\mathrm{n}}, \mathrm{O}_{\mathrm{n}}{ }^{-}\left(\mathrm{CO}_{3}\right)$ and $\mathrm{CO}_{3}{ }^{-}\left(\mathrm{H}_{2} \mathrm{O}\right)_{\mathrm{n}}$. The flux of ions created from air species such, $\mathrm{NO}^{+}$and $\mathrm{O}_{3}{ }^{-}$, are seen to be maximized a distance of several $\mathrm{mm}$ from 1 the nozzle, whereas the $\mathrm{He}^{+}$concentration continually decreases with distance from the exit 2 orifice. The time-resolved measurements (time-resolution down to $2 \mu \mathrm{s}$ ) show positive ions 23 appear twice in one full period of the voltage waveform, correlated directly with positive and 24 negative current peaks. The rise and fall times of the positive ions are typically tens of $\mu$ s. In 25 contrast, the appearance of negative ions is correlated only with the negative part of discharge current, with one main peak in the detected ionic flux seen per cycle. The rise time of the negative ions is about $10 \mu \mathrm{s}$, independent of mass, however we observed longer decay times from 100 to $150 \mu$ s increasing with mass. With increased driving frequency, the time 
1 modulation in the ionic fluxes is reduced, particularly for the negative species that show 2 almost constant fluxes at $25 \mathrm{kHz}$ throughout the cycle. The observations can be understood 3 through a simple picture of the interaction of the He jet and the moist ambient air. The results 4 indicate that the discrete plasma "bullets" and their afterglow tail, that forms the jet, carry an 5 associated positive or negative current depending on the time of their creation in the voltage 6 cycle. 


\section{Introduction}

Low-pressure plasma discharges are a useful tool in a number of surface treatment and polymerisation applications, since the plasma can act isotropically on irregular surfaces in large volumes whilst delivering good uniformity on substrates of all sizes [1]. In recent years, however, there has been much interest in developing plasmas on the micro-scale which operate at, or close to atmospheric-pressure [2] to deliver cheap processing solutions with opportunities to functionalise surfaces on the small scale. One candidate plasma device is the atmospheric-pressure plasmas jet (APPJ) [3], which can be operated in different gases and is technologically simple, environmentally-friendly and very economical. The application areas of APPJs include material etching [4], deposition [5], surface modification [6], sterilization [7][8] and in biomedicine such as a wound treatment [7] taking advantage of the very low temperature plasma produced in(to) the ambient air. There are two well known configurations namely the plasma pencil [9] and the plasma needle [10]. Recently, plasma jets, which produce a plasma plume emerging for a fine capillary have been scaled down to produce treatment on the nano-scale (down to tens of nm) [11].

To accompany the technological development, a number of researchers have undertaken advanced diagnostic studies to understand the internal physical and chemical phenomena in APPJs. These include the use of voltage-current probes [12], optical emission spectroscopy (OES) to get gas temperatures [13][14] from emission profile and electron density from Stark broadening [15], 2-D imaging to observe plasma bullet development [16], laser absorption spectroscopy (LAS) [11] and two-photon absorption laser induced fluorescence (TALIF) techniques [17] to determine the density of atoms, Schlieren photograph [18] to observe the invisible gas dynamics and recently molecular beam mass spectrometry [19][20][21][22] [23][24] to determine the ionic composition (both negative and positive ions) from APPJs.

Here we show for the first time the temporal evolution of the mass-selected ionic species in the plasma plume as it interacts with ambient air and correlate the rise and fall of the ionic flux of which the current carried by plasma bullets as they are transported down the plume. In a number of previous mass spectroscopic studies of plasma at atmospheric pressure using an 
1 array for different source configurations (not just the $\mu$-APPJ), the emphasis has been on

2 understanding the plasma composition in complex gases or gas mixtures, such air [19], $\mathrm{N}_{2}-\mathrm{O}_{2}$

3 mixtures [20], He-air [21][22], $\mathrm{He}_{-} \mathrm{O}_{2}$ [23] or He-water mixtures [24] as a feed gas. However,

4 here we concentrate on using a pure $\mathrm{He}$ jet and study its interaction with the ambient

5 environment creating secondary ionic species, outside of the main discharge.

6

7 2. The experimental arrangement

\section{$2.1 \quad \mu$-plasma jet setup}

9 The $\mu$-plasma jet used in this study was made using a $15 \mathrm{~cm}$ long quartz glass tube of 1 $10 \mathrm{~mm}$ inner diameter (ID) and $3 \mathrm{~mm}$ outer diameter (OD) on which two copper ring electrodes 11 of $8 \mathrm{~mm}$ length were attached as shown in figure 1 . The electrode close to the outflow was powered by high ac voltages $\left(6-9 \mathrm{kV}, \mathrm{V}_{\mathrm{p}-\mathrm{p}}\right)$ over a range of frequencies $(5-25 \mathrm{kHz})$. The

13 power supply consisted of a sine wave oscillator (Farnell, LF1) driving a commercial audio 14 amplifier (HQ power, VPA2350MB) with a voltage step-up transformer (Express 15 Transformers, UK) at the output stage to generate the required high voltages for discharge breakdown. The second electrode was electrically grounded. The jet struck in helium gas (99.996\% purity), was operated essentially as a dielectric barrier discharge (DBD), with gas flow rates (between 0.2 and $5.4 \mathrm{~L} \mathrm{~min}^{-1}$ ), and controlled using a manual rotameter (Omega Engineering). The flexible design allowed the separation and position of the ring electrodes to be changed on the glass tube to aid breakdown and optimise the visible jet length. After preliminary investigations, a gap separation of $25 \mathrm{~mm}$ was chosen for all subsequent experiments with a fixed He flow rate of 1.38 slm producing visible plumes of $12 \mathrm{~mm}$ in length. To obtain 2-D spatially resolved mass spectroscopic measurements, the $\mu$-plasma jet was mounted on an $x-y$ stage, having a travel range of $20 \mathrm{~cm}$ in the axial direction and $12 \mathrm{~cm}$ in the radial with $1 \mathrm{~mm}$ spatial resolution with the stage placed in front of the mass spectrometer entrance orifice.

\subsection{Molecular beam mass spectroscopy}


1 The molecular beam mass spectrometer (MBMS) used here was a quadrupole-based mass 2 spectrometer (QMS) system, the HPR-60 MBMS (from Hiden Analytical Ltd.) having a 3 three-stage differentially pumped inlet system separated by aligned skimmer cones and turbo 4 molecular pumps. The pressure reduction stages, $\left(\mathrm{P}_{1}\right)-\left(\mathrm{P}_{3}\right)$ shown in figure $1(\mathrm{a})$, provide a 5 pressure reduction from atmospheric-pressure to $10^{-1}$ Torr at the $\left(\mathrm{P}_{1}\right), 10^{-5}$ Torr at the $\left(\mathrm{P}_{2}\right)$ and $610^{-7}$ Torr at the $\left(\mathrm{P}_{3}\right)$ stage. A molecular beam is formed which is directed into the QMS. 7 Positive and negative ions, generated by the jet (either between the electrodes or through 8 interactions in ambient air) were readily detected, with a mass resolution of 0.01 amu and with an upper mass range of 300 amu. The instrument can also be used in residual gas analyzer (RGA) mode, having an internal ionisation source in the last pressure redactor stage. The mass spectrometer was operated in secondary ion mass spectroscopy (SIMS) mode, with a time resolution of $10 \mu$ s down to $2 \mu$ s depending on plasma frequency, obtained by gating the detector using an internal gate signal synchronized to the driving voltage waveform.

The end of the jet capillary was aligned with the centre of the sampling orifice $(100 \mu \mathrm{m}$ diameter) and the (nozzle-orifice) distance $d$ were varied from 1 to $15 \mathrm{~mm}$. Preliminary investigations showed that ionic signals could only be detected with the plasma plume parallel to the axis of the instrument, that is, no ions were detected at radial distances greater than the plume width of $1 \mathrm{~mm}$ (close to the spatial resolution of the $x$-y stage). The sampling time of the detector was set at $1 \mathrm{~s}$ and ions, both positive and negative, of masses between 1 and 100 amu were collected.

21 To restrict the amount of data in subsequent experiments we chose just three measurement positions in the visible plume, namely at $d=1,7$ and $11 \mathrm{~mm}$, each position showing different interactions of the emerging $\mathrm{He}^{+}$and the ambient air. Three different driving frequencies $(5$, 10 and $25 \mathrm{kHz}$ ) were also used, providing temporal resolutions of 10, 5, and $2 \mu$ s. Since ions have a significant travel time in the instrument dependent on their mass, to correlate properly the time of their entrance into the instrument and the phase of the voltage cycle, the detection signals were temporally corrected using an algorithm developed at Hiden Analytical Ltd [25].

\subsection{Discharge and bullet current measurements}


1 To interpret the temporal mass spectroscopic measurements, a correlation to the discharge

2 current and voltage waveforms is necessary. The main discharge current $I_{\mathrm{T}}$ (flowing between

3 transformer and the driving electrode) was measured using a current probe 1 (Tektronix 4 TCP0030) (see figure 1(b)), with a $120 \mathrm{MHz}$ bandwidth. The electrode voltage was measured with a high voltage probe (HVP-15HF). Both $V$ and $I$ were displayed on a digital oscilloscope (DPO3034). $I_{\mathrm{T}}$ was averaged over 128 cycles, and the large and continuous sinusoidal displacement current $I_{\mathrm{d}}$ observed in the waveform, (which can be measured without gas flow), was removed from the total signal to give the true discharge current $\left(I_{\mathrm{D}}=I_{\mathrm{T}}-I_{\mathrm{d}}\right) . I_{\mathrm{D}}$ is composed of the internal discharge current and the free-stream "bullet" current $I_{\mathrm{b}}$. Figure 2 shows waveforms for (a) driving voltage, (b) currents, total $I_{\mathrm{T}}$ and discharge currents $I_{\mathrm{D}}$, and (c) bullet current for a sinusoidal driving voltage $8 \mathrm{kV}\left(\mathrm{V}_{\mathrm{p}-\mathrm{p}}\right)$ of frequency 10 $\mathrm{kHz}$. The bullet current (described below) was measured $7 \mathrm{~mm}$ downstream and the discharge and bullet current peaks coincide in this electrode arrangement because $I_{\mathrm{D}}$ flow to two pathways, toward the upstream ground electrode and downstream towards the external ground, of roughly equal distance for the driving electrode. The current peaks are several milli-amperes or less, much smaller than the displacement current (few tens $\mathrm{mA}$ ) as showing in figure 2(b). The width of the current pulse (FWHM) is several micro-seconds. For the bullet current measurements in the outflow, a metal collector plate (copper), connected to the ground line was used and $I_{\mathrm{b}}$ flowing in this circuit was monitored by the current probe 2 . The presence of the metal collector perturbs the free-stream conditions of the plasma plume, however it gives the same electrical conditions as used in the MBMS measurements, where the sampling orifice of the mass spectrometer acted as an external grounded electrode.

\section{$2.4 \quad 2-D$ imaging}

The visible plasma jet and plasma bullet investigations were carried out using both timeaveraged and time-resolved 2-D broadband optical imaging, utilising an ICCD camera (Andor, DH520-18F-01). To determine the total length of the visible plume as shown in figure 3(a) an ICCD exposure time of $0.5 \mathrm{~s}$ was used. To resolve individual plasma bullets (known to be present in the plume and correlated to the positive and negative excursions of 
1 the voltage waveform [11][26]) a $100 \mathrm{~ns}$ gating time was used, controlled by a trigger pulse

2 (from a Stanford Research Systems, DG645 Digital Delay Generator), synchronized to the

3 driving voltage at time $t=0$. The time-resolved image of a single plasma bullet in figure 3(b)

4 was taken at a delay time $(=35.6 \mu \mathrm{s})$ from which we can distinguish an intense emission head

5 ('bullet head') and a long and faint tail ('bullet halo'). This feature will be discussed later in

6 the context of the MBMS results. The time for the bullet head to pass a fixed point was

7 observed to be few hundred ns but the bullet tail was seen to persist for significantly longer,

8 almost the entire time to the emergence of the next main discharge event. From observation

9 of the bullet head we have calculated the a propagation speed for the bullet of a few tens of

10 kilometre per second, in very good agreement with previous reports [2][16][18]. This is much

11 faster than the gas speed of a few tens metre per second. The current pulse (recorded in the

12 driving circuit corresponding to this bullet) is shown in figure 2(c).

\section{Results and discussion}

\subsection{Positive ions}

Figure 4(a) and (b) shows the time-averaged mass spectra of positive and negative ions obtained $7 \mathrm{~mm}$ from the exit of the capillary along the discharge axis. The excitation voltage was $8 \mathrm{kV}$ at $10 \mathrm{kHz}$ frequency and the flow rate was fixed at $1.38 \mathrm{~L} \mathrm{~min}^{-1}$. The raw mass spectra data has been converted to a relative yield $(\%) Y=Y_{\mathrm{i}} / \Sigma_{\mathrm{i}} Y_{\mathrm{i}}(\%)$, where $Y_{\mathrm{i}}$ is the count intensity of a specific species. Ions up to 100 amu have been detected. The positive ion spectra in figure 4(a) reveals singly charged ions, namely $\mathrm{He}^{+}$originating from the primary discharge and another 11 species, created through jet-air interactions. We observed no doubly charges species. These are by $\%$ yield, $65.3 \%$ of $\mathrm{N}_{2}{ }^{+}$and $21.1 \%$ of $\mathrm{O}_{2}{ }^{+}$, as well as small portions of $\mathrm{N}^{+}, \mathrm{O}^{+}, \mathrm{N}_{2} \mathrm{H}^{+}, \mathrm{NO}^{+}$and $\mathrm{Ar}^{+} . \mathrm{CO}_{2}{ }^{+}$is also observed but its concentration is less than $0.02 \%$. The general composition of ions is consistent with those in atmospheric air as shown in table 1.

$\mathrm{He}^{+}$ions detected here are created inside the capillary (the primary discharge) via electronneutral ionization processes in the transverse electric field between electrodes, namely R1) $\mathrm{e}^{-}$ 
$1+\mathrm{He} \rightarrow 2 \mathrm{e}^{-}+\mathrm{He}^{+}$and R2) $\mathrm{e}^{-}+\mathrm{He}_{m} \rightarrow 2 \mathrm{e}^{-}+\mathrm{He}^{+}$, where $\mathrm{He}_{m}$ is the $2^{3} \mathrm{~S}$ state metastable helium.

2 Both $\mathrm{He}^{+}$and $\mathrm{He}_{m}$ species are transported outside the capillary by the mass flow action of the

3 He gas flowing with a speed of $30 \mathrm{~m} \mathrm{~s}^{-1}$. No helium dimer ions $\left(\mathrm{He}_{2}^{+}\right)$were detected in this

4

5

6 work. This may be due to the measurement only being made outside capillary where charge transfer between $\mathrm{He}_{2}{ }^{+}$and $\mathrm{N}_{2}$ and/or $\mathrm{O}_{2}$ molecules may readily deplete the $\mathrm{He}_{2}{ }^{+}$signal as it exits the nozzle.

A number of secondary positive ion are produced through the interaction of the emerging jet and ambient air. For instance, molecular nitrogen ions $\mathrm{N}_{2}{ }^{+}$are created by a number of possible reactions R3) $\mathrm{He}_{2}{ }^{+}+\mathrm{N}_{2} \rightarrow 2 \mathrm{He}+\mathrm{N}_{2}{ }^{+}\left(8.3 \times 10^{-10} \mathrm{~cm}^{3} \mathrm{~s}^{-1}\right)$ [27] and $\left.\mathrm{R} 4\right) \mathrm{He}_{m}+\mathrm{N}_{2} \rightarrow$ $\mathrm{He}+\mathrm{N}_{2}{ }^{+}+\mathrm{e}^{-}\left(5 \times 10^{-11} \mathrm{~cm}^{3} \mathrm{~s}^{-1}\right)$ [28], however as we have said no $\mathrm{He}_{2}{ }^{+}$was detected in these studies and R3) might be unlikely. For $\mathrm{O}_{2}{ }^{+}$production, possible reactions are R5) $\mathrm{He}_{m}+\mathrm{O}_{2} \rightarrow$ $\left.\mathrm{He}+\mathrm{O}_{2}{ }^{+}+\mathrm{e}^{-}\left(2.54 \times 10^{-10} \mathrm{~cm}^{3} \mathrm{~s}^{-1}\right), \mathrm{R} 6\right) \mathrm{He}^{+}+\mathrm{O}_{2} \rightarrow \mathrm{He}+\mathrm{O}_{2}{ }^{+}\left(3.3 \times 10^{-11} \mathrm{~cm}^{3} \mathrm{~s}^{-1}\right)$, and R7) $\mathrm{He}^{+}+\mathrm{O}_{2}{ }^{*}$ $\rightarrow \mathrm{He}_{+} \mathrm{O}_{2}{ }^{+}\left(3.3 \times 10^{-11} \mathrm{~cm}^{3} \mathrm{~s}^{-1}\right)$, where $\mathrm{O}_{2}{ }^{*}$ is the metastable molecule (state ${ }^{1} \Sigma_{\mathrm{g}}^{+}$). The rate constants R5-R7 have been used in the modelling of both atmospheric pressure [23] and low pressure plasmas [29]. The reaction rate for the charge transfer from $\mathrm{He}^{+}\left(\right.$or $\mathrm{He}_{2}^{+}$) and the ionisation by $\mathrm{He}_{m}$ to both $\mathrm{N}_{2}$ and $\mathrm{O}_{2}$ are similar in order $\left(\sim 10^{-11}\right.$ to $\left.10^{-10} \mathrm{~cm}^{3} \mathrm{~s}^{-1}\right)$. Therefore, the positive ion yield should reflect the composition of the ambient air. It therefore stands to reason that $\mathrm{N}_{2}{ }^{+}$was the highest yield with $\mathrm{O}_{2}{ }^{+}$the second highest.

\subsection{Negative ions}

For the negative ions, we detected 34 species as shown in figure 4(b). Many of these are clusters and therefore more massive than the positive ions. It is well known that the negative ions are produced by the dissociative electron attachment. The main ionic species by relative abundance are $22.7 \%$ of $\mathrm{O}_{3}^{-}, 10.5 \%$ of $\mathrm{O}_{2}^{-}\left(\mathrm{H}_{2} \mathrm{O}\right), 8.2 \%$ of $\mathrm{OH}^{-}\left(\mathrm{H}_{2} \mathrm{O}\right)_{2}, 6.4 \%$ of $\mathrm{O}_{3}{ }^{-}\left(\mathrm{H}_{2} \mathrm{O}\right)$, $5.8 \%$ of $\mathrm{OH}^{-}\left(\mathrm{H}_{2} \mathrm{O}\right), 5.4 \%$ of $\mathrm{O}_{2}^{-}, 1.9 \%$ of $\mathrm{O}^{-}, 0.8 \%$ of $\mathrm{OH}^{-}$and also clusters, $\mathrm{O}_{\mathrm{n}}^{-}\left(\mathrm{H}_{2} \mathrm{O}\right)_{\mathrm{m}}$, $(\mathrm{OH})_{\mathrm{n}}{ }^{-}\left(\mathrm{H}_{2} \mathrm{O}\right)_{\mathrm{m}}, \mathrm{O}_{\mathrm{n}}{ }^{-}\left(\mathrm{CO}_{3}\right), \mathrm{CO}_{3}{ }^{-}\left(\mathrm{H}_{2} \mathrm{O}\right)_{\mathrm{n}}$, and so on. Table 1 provides the complete set of species with relative percentage yields, showings that clusters dominate the spectrum of negative ions. This is because not only do negative ions form through dissociative electron 
1 attachment $\left(\mathrm{e}+\mathrm{AB} \rightarrow \mathrm{A}^{-}+\mathrm{B}\right)$ [24] but the product ions readily undergo further attachment

2 processes $\left(\mathrm{A}^{-}+\mathrm{M} \rightarrow \mathrm{A}^{-} \mathrm{M}\right)$, where $\mathrm{M}$ denotes molecules in air, to form heavier species.

3 The dissociative electron attachment of $\mathrm{H}_{2} \mathrm{O}$ and subsequently hydration has been reported

4 for negative ion formation in Ref. [24] where a He-water mixture was used to produce moist

5 gas, then fed into a glow discharge in an isolated space (not exposure to air). In our work,

6 however, the most intense peaks of negative ions are oxygen molecules such as $\mathrm{O}_{3}{ }^{-}, \mathrm{O}_{2}{ }^{-}$

$7 \quad\left(\mathrm{H}_{2} \mathrm{O}\right)$ and $\mathrm{O}_{3}{ }^{-}\left(\mathrm{H}_{2} \mathrm{O}\right)$, indicating the main pathway of creation is through dissociative electron

8 attachment of $\mathrm{O}_{2}$ and subsequent oxidisation to form many of the negative ion species. From

9 the data in table 1 we also see the overall yield for oxygen containing molecule ions $\left(\mathrm{O}_{\mathrm{n}}{ }^{-}\right)$is

$1045 \%$, while the overall yield for hydroxyl $(\mathrm{OH})_{\mathrm{n}}{ }^{-}$containing ions is $25 \%$. This indicates that

11 here atmospheric molecular oxygen is more important than water vapour in the production of

12 negative ions. To illustrate this, to produce $\mathrm{O}_{3}{ }^{-}$, we can considered two possible routes, the

13 dissociative electron attachment of both $\mathrm{O}_{2}$ and water, $\left.\mathrm{R} 8\right) \mathrm{e}^{-}+2 \mathrm{O}_{2} \rightarrow \mathrm{O}^{-}+\mathrm{O}+\mathrm{O}_{2}$ and R9) $\mathrm{e}^{-}$

$14+\mathrm{H}_{2} \mathrm{O}+\mathrm{O}_{2} \rightarrow \mathrm{O}^{-}+\mathrm{H}_{2}+\mathrm{O}_{2}$, followed by attachment $\left.\mathrm{R} 10\right) \mathrm{O}^{-}+\mathrm{O}+\mathrm{O}_{2} \rightarrow \mathrm{O}_{3}{ }^{-}+\mathrm{O}$. R8 and R9

15 reactions have similar cross sections for dissociative electron attachment [30][31]. Since the

16 concentration atmospheric $\mathrm{O}_{2}$ is at least 50 times greater than that of water molecules in the

17 air, even in humid conditions, the main reaction route for formation of $\mathrm{O}_{3}{ }^{-}$is a series of $\mathrm{R} 8$ and R10. Our observations of a high content of species like $\mathrm{O}_{3}{ }^{-}$and $\mathrm{O}_{2}{ }^{-}\left(\mathrm{H}_{2} \mathrm{O}\right)$, and few species such as $\mathrm{OH}^{-}\left(\mathrm{H}_{2} \mathrm{O}\right)$ as also found in [24] is due to the presence of atmospheric oxygen

20 (contained in moisture free) which become mixed or entrained in the He gas flow.

21 Since the positive and negative ions are formed through wholly different processes it is expected that each process may be separated spatially and temporally. To understand better the processes leading to ionic formation, time-resolved mass spectroscopy has been carried out at a number of locations along the visible glow and the results are discussed in section 3.4 below.

\subsection{Spatial distribution of ionic concentrations}

Figure 5(a) and (b) shows the relative concentration of selected positive and negative ions detected along the length of the plasma plume, from $1 \mathrm{~mm}$ from exit of the capillary to a 
1 maximum distance of $15 \mathrm{~mm}$. The ions can be detected inside of the visible plume and up to

2 a more few mm outside the plume along the axis, a region characterised by laminar (non3 turbulent flow) He gas flow [18][32]. One should note that the mass spectrometer flange 4 containing the sampling orifice can act as an external electrode (being grounded) and so 5 changing the mass-spectrometer capillary distance will affect the discharge. The visible 6 extension of the plume (viewed by eye and ICCD camera) was measured to around $12 \mathrm{~mm}$. 7 See the image in figure 3(a).

8 The positive and negative ion species show some differences in behaviour. For the positive 9 ions in figure 5(a), we see the $\mathrm{He}^{+}, \mathrm{N}_{2}{ }^{+}$and $\mathrm{O}_{2}{ }^{+}$concentrations remains high up to a distance 10 of $6 \mathrm{~mm}$, after which there is peak of width $3 \mathrm{~mm}$ followed by a drop of 4 orders of 11 magnitude to no discernable signal between 14 and $15 \mathrm{~mm}$. The peak intensity midway along 12 the plume coincided with a very strong rise in $\mathrm{NO}^{+}$, and also $\mathrm{N}_{2}{ }^{+}$and $\mathrm{O}_{2}{ }^{+}$intensities between 137 and $11 \mathrm{~mm}$. In this region there must be strong mixing of air with jet exhaust. The negative ion concentrations in figure 5(b) show no outstanding strong peak midway along the plume but there is gradual rise is in the heavy $\mathrm{O}_{3}{ }^{-}$signal beginning at $7 \mathrm{~mm}$ where the positive ions intensities increase. The intensities remain constant before falling rapidly beginning at $12 \mathrm{~mm}$, which corresponds to the tip of visible plume, as shown in figure 3(a). The light species such as atomic $\mathrm{O}^{-}$are terminated more quickly than the heavier species such as $\mathrm{O}_{3}{ }^{-}$. The velocities of the ions may be mass dependent; however we have no information on the energy of the ions in the plasma plume. Clearly comparing positive and negative ions in figure 5(a) and (b) we see the negative ions extend further past the end of the visible plume than the positive species, being still detectable at $15 \mathrm{~mm}$.

\section{$23 \quad 3.4$ Time-resolved SIMS, 2-D imaging and current measurements}

24 Since the first work conducted in the group of Engemann [16] it has been shown many times that the visible plasma emission extending from the DBD micro-jet propagates at very fast speeds (up to $\sim 10^{2} \mathrm{~km} \mathrm{~s}^{-1}$ ) in the form of discrete packets referred to as plasma "bullets". Recently, it is also reported that for ac driven APPJs, bullets have their origin when the driving voltage reaches a threshold in the positive and negative going parts of the voltage 
1 cycle [26]. In brief, the plasma bullet triggered from positive half period shows an intense

2 and bright emission. While negative half period bullet is observed faint and broad. However,

3 initiation of both is localised around few $\mathrm{mm}$ and can be clearly observed only within

4 duration of a few microseconds after initiation.

5 The ionic content of the bullet (its head and following tail or halo) has not yet been

6 determined. Here, through time-resolved measurements $\left(\mathrm{He}^{+}\right.$and secondary positive and 7 negative) ions we can correlate the time over which ionic species rise, persist and 8 subsequently fall during the voltage cycle to the time the bullet of length $\sim 12 \mathrm{~mm}$ (consisting 9 of head and tail) passes a point in space.

10 For the time-resolved MBMS studies, the mass selected ion concentrations were measured 11 at three distances 1,7 and $11 \mathrm{~mm}$ from the exit orifice of the capillary over two whole 12 periods of the driving voltage (e.g. this is $400 \mu \mathrm{s}$ when operating at $5 \mathrm{kHz}$ ). The time13 resolution of the ionic concentrations (both positive and negative) changed depending on the 14 driving frequency, i.e. $10 \mu \mathrm{s}$ at $5 \mathrm{kHz}$ and $2 \mu \mathrm{s}$ at $25 \mathrm{kHz}$. To aid interpretation, we have chosen to display a 6 positive species $\left(\mathrm{O}_{2}^{+}, \mathrm{O}^{+}, \mathrm{N}_{2}{ }^{+}, \mathrm{N}^{+}, \mathrm{He}^{+}\right.$and $\left.\mathrm{Ar}^{+}\right)$and 6 negative species $\left(\mathrm{O}^{-}, \mathrm{OH}^{-}, \mathrm{O}_{3}^{-}, \mathrm{OH}^{-}\left(\mathrm{H}_{2} \mathrm{O}\right)\right.$ and $\left.\mathrm{H}_{2} \mathrm{O}^{-}\right)$, having a behaviour and response representative of all the ions detected as listed in table 1 and shown in figure 4.

\subsubsection{Effect of distance}

Figure 6 to 8 shows the temporal evolution of the ionic species together in each figure with the driving voltage waveform, the discharge current $I_{\mathrm{D}}$ and local bullet current $I_{\mathrm{b}}$ measurements. The relative concentrations of the positive and negative species reflect the time-average mass spectra in figure 4 with the most intense species being $\mathrm{N}_{2}{ }^{+}$and $\mathrm{O}_{2}{ }^{+}$for the positive ions $\mathrm{O}_{3}{ }^{-}$and $\mathrm{O}^{-}$for the negative ions. The magnitude of the positive and negative local bullet currents $I_{\mathrm{b}}$ follow those of the general ionic intensity, i.e. small currents are associated with small ionic intensities. So we can see the passing bullet delivers positive ionic species to the instrument in each voltage half cycle.

All the three figures 6-8, show the same strong features. In the positive voltage half cycle with an associated positive discharge current pulse (and directly correlated with the start of 
1 the local bullet current) we observe a sharp rise in the positive ion concentration (by 3 orders

2 of magnitude) within about $10 \mu \mathrm{s}$. When two current peaks appear, in either of the positive or

3 negative parts of the voltage cycle, as seen clearly in figure 6 , we also observe two peaks in

4 the positive ion intensities, correlated directly to the features in the current. Fast positive ion

5 rise times may be due to rapid electron induced collisional ionisation with ions and neutrals.

6 The electrons will be streaming in the direction from the external ground toward the positive

7 electrode on the capillary. This is sustained for about $50 \mu$ s after which the ionic intensities

8 fall all at similar rates. Interestingly, we also observe a clear and rapid rise in the positive

9 ionic intensities on the negative voltage half cycle correlated to the negative discharge current

10 (and local bullet current measurement). The positive ion intensities are however clearly

11 weaker in this part of the voltage cycle. This may be due to the reduction in the ionisation rate of neutrals to form positive ions via electron collisions in this part of the cycle as the electrons are readily attached in great numbers to form negative ions.

14 For the case of the negative ions, their rise to correlated to the negative part of the voltage cycle, reaching their peak on fast time-scales $(\sim 10 \mu \mathrm{s})$ similar to the positive ions, but they persist for much longer sustaining times up to $100-150 \mu$ s, displaying much slow decays, and showing little response to the subsequent positive voltage half cycle. The correlation of negative ions with negative voltage swings on the powered electrode may be associated with the axial electric field which will act to accelerate electrons out into the plume, where they readily attach to molecules in dissociative reactions to form families of negative ions. In the positive half cycle the concentration of electrons in the plume may be reduced as the powered electrodes acts as an effective electron sink.

The negative ions, with decay time constants $\tau \sim 20 \mu$ s display a modulation once every cycle rather than a twice as with the positive ions. We may be able to understand that heavier species, such as negative ion clusters will have lower mobilities and longer lifetimes in air than the lighter positive ions [23], however here $\mathrm{O}^{-}$displays decay times many times longer than $\mathrm{O}^{+}$(see figure 6 to 8). It is reported that ions such as $\mathrm{OH}^{-}$can have lifetime of $1 \mathrm{~ms}$ 
1 being stable in air [33] however primary ions in reactions such as $\mathrm{O}^{-}$have shorter lifetimes

2 and short mean free paths of about $0.1 \mu \mathrm{m}$.

3 Close inspection of the figure 6 to 8 shows there is some small modulation of the measured

4 intensities of the lighter ions $\mathrm{O}^{-}, \mathrm{H}^{-}$and $\mathrm{OH}^{-}$in the positive half cycle of the voltage. With 5 increasing distances, it is clear that atomic $\mathrm{O}^{-}$flux is reduced. The fluxes of heavy molecules,

$6 \mathrm{O}_{3}{ }^{-}$and $\mathrm{OH}^{-}\left(\mathrm{H}_{2} \mathrm{O}\right)$, are maximised at the $7 \mathrm{~mm}$ where a strong interaction between plasma jet

7 and surrounding air is expected as mention above subsection 3.3.

8 The amount of mixing of the air with the He stream will be an important factor in 9 determining the amount of negative ionic species (clusters) detected in the plume created 10 through reactions $\mathrm{R} 8$ and $\mathrm{R} 9$, and then by further oxidisation and/or hydration processes.

11 It is clear in figure 6 to 8 that both the discharge current and the locally measured current in 12 the plume (bullet current) consist of a rapid pulse of width of only several microseconds; 13 however the peaks ionic spectra last much longer ( $\sim 50$ s and $\sim 100 \mu$ s for the positive and negative ions respectively).

15 Inspection of the bullet current waveforms (for example that in figure 2(c)), shows the head contains most of the total charge associated with bullet with about $25 \%$ contained in the long tail. For positive currents the head contains positive ions and few negative ions $(<10 \%)$ which are decaying in density from the previous pulse. The duration of tail which also consists mostly of positive ions passing any point coincide with the duration of the positive ionic signals in mass spectroscopic results. For negative going bullet currents the head contains a high proportion of negative ions and some positive ions (as shown in mass spectroscopic results in figure 6). In this case, the bullet tail contains negative ionic species.

\subsubsection{Ionic life-times}

24 For bullet formation outside the capillary, we see a bright head of length typically 2-3 mm followed by a visually weaker but attached tail. As the head advances (with velocities up to $23 \mathrm{~km} \mathrm{~s}^{-1}$ measured using the ICCD camera), the tail elongates, being essentially clamped to the end of the capillary for at least $10 \mu \mathrm{s}$ observed before the next main discharge event, see also [2][16][34][35][36][37]. Even when the bullet is terminated at the external grounded 
1 electrode (or current collector), the bullet tail persists for some time. In free stream conditions,

2 it has been observed that after about several $\mu$ s the bullet head dissipates, as the mole fraction

3 of He gas in ambient air falls below a critical value as turbulence sets in to the flow [18].

4 The results from the time-resolved mass spectrometric measurements here show remarkably

5 long times for the existence of both positive and negative species, between $\sim 50$ and $\sim 150 \mu$ s

6 respectively. This time-scale is much longer that the time the bullet traverses between the

7 capillary end and the mass spectrometer orifice, and longer than the time we observe the

8 optical emission from the long bullet tail. However, although the tail is not observed some 50

$9 \mu$ s after the bullet initiation we argue that the passing bullet has created a halo of secondary

10 positive and negative ions which have significant life-times. The fast increase in ionic signal

11 for both polarity ions (10 $\mu$ s rise time), correlated with the local bullet current measurement

12 is characteristic of the creation of species as electrons (or possibly $\mathrm{He}^{+}$) ions rapidly pass

13 through the gas. Once created, the negative ions (including heavy clusters) have longer

14 lifetimes than the positive species, possibly due to higher ionic stabilities, more complex

15 destruction reaction routes or lower ion mobilities in the ambient air [33][38]. The distance

16 over which ions travel to the mass spectrometer from their point of creation can be

17 determined, from knowledge of the lifetimes and the speed of the gas that transports them

18 downstream. Here we have a He gas speed of $30 \mathrm{~ms}^{-1}$ and assuming 50-100 $\mu$ s lifetimes it

19 gives a distance of about 1.5 to $3 \mathrm{~mm}$. It seems likely therefore that the detected species both

20 positive and negative ions have been created close to the spectrometer orifice, however coming from distance much greater than reported elsewhere [38] and this we cannot explain with the limited data of this study.

\subsubsection{Effect of driving frequency}

The ionic intensities measured for pulse frequencies of 10 and $25 \mathrm{kHz}$ are shown in figures 9 and 10 respectively. It is clear that the peak ionic fluxes are reduced at higher frequencies. Also, we see only one current peak per half cycle of the discharge voltage. These observations are not understood but will be explored in further studies. At $25 \mathrm{kHz}$ the negative ions respond less well the voltage modulation, however the positive ions intensities 
1 still show a clear time modulation, with $10 \mu$ s rise and decay times similar to those in figures

2 6-8 for a $5 \mathrm{kHz}$ frequency. The $\mathrm{N}_{2}{ }^{+}$and $\mathrm{O}_{2}{ }^{+}$signals rise and fall as before at other frequencies

3 but atomic ions, $\mathrm{N}^{+}$and $\mathrm{O}^{+}$, are delayed around $10 \mu$ s relative to these, this may be due to the

4 stepwise process necessary to produce atomic ions from air species. For the negative ions, at

$5 \quad 10$ and $25 \mathrm{kHz}$ the atomic $\mathrm{O}^{-}$and $\mathrm{OH}^{-}$molecule intensities are measured in advance of the

6 heavier ions such as $\mathrm{O}_{3}^{-}, \mathrm{O}_{2}^{-}\left(\mathrm{H}_{2} \mathrm{O}\right), \mathrm{OH}^{-}\left(\mathrm{H}_{2} \mathrm{O}\right)_{2}, \mathrm{O}_{3}{ }^{-}\left(\mathrm{H}_{2} \mathrm{O}\right)$ and $\mathrm{OH}^{-}\left(\mathrm{H}_{2} \mathrm{O}\right)$, this may also be due

7 to multi-step processes necessary for their creation and possibly longer travel times from the

8 point creation to the mass spectrometer orifice.

9 Although we see almost a flat response in the negative ion signal at $25 \mathrm{kHz}$, inspection of

10 the curves on a linear scale reveal the same rise and decay time constant as for 5 and $10 \mathrm{kHz}$.

11 At $25 \mathrm{kHz}$, half the period is $20 \mu \mathrm{s}$, close to the decay time constant for the negative ions;

12 hence it is possible that an equilibrium concentration along the plume of negative ions may

13 develop with only a small modulation in intensities during the voltage cycle, as can be seen in

14 figure 10.

\section{Conclusions}

17 Using time-resolved molecular beam mass spectrometry negative and positive ions have been detected in the output plume of an atmospheric pressure plasma micro-jet operating in $\mathrm{He}$ at $5-25 \mathrm{kHz}$. The results show that positives ions (for instance $\mathrm{He}^{+} \mathrm{N}_{2}{ }^{+}$and $\mathrm{O}_{2}{ }^{+}$) are created on the positive and negative voltage swings and persist for about $50 \mu$ s. The creation of negative ions (e.g. $\mathrm{O}_{3}{ }^{-}, \mathrm{O}_{2}{ }^{-}\left(\mathrm{H}_{2} \mathrm{O}\right), \mathrm{OH}^{-}\left(\mathrm{H}_{2} \mathrm{O}\right)_{2}, \mathrm{O}_{3}{ }^{-}\left(\mathrm{H}_{2} \mathrm{O}\right), \mathrm{OH}^{-}\left(\mathrm{H}_{2} \mathrm{O}\right)$ and clusters) is correlated however only to the negative part of the voltage cycle, but these species have very long decay times ( 3 or 4 times longer for the full decay than the positive ions). The ionic components are only observed in the visible plasma plume and up to 1 to $2 \mathrm{~mm}$ distance beyond its end.

The temporal increase of the signal of both positive and negative ionic species in the mass spectra is correlated directly with the rise of the discharge and local bullet currents. The current from the head of individual bullets only exists for several microseconds, much shorter 
1 than the detected time of the ionic species (50 to $150 \mu \mathrm{s})$. As the bullet head passes through

2 the neutral (non-turbulent) He stream, it produces a halo of secondary ions of both polarities.

3 Inspection of the bullet current waveforms together with time-resolved optical imaging and

4 mass spectroscopic results indicates that the bright head of the bullet contains most of the net

5 space charge, with the faint bullet tail (halo) of lower space charge persisting for long times

6 over which the ionic species are detected. At highest frequency of $25 \mathrm{kHz}$, when half the

7 driving period becomes close to the characteristic decay time of the negative ions a constant

8 (almost equilibrium) concentration of negative ions can be maintained adjacent to the orifice

9 of the mass spectrometer.

10

11 Acknowledgement

12 We thank Mr. Alan Roby for the construction of the microplasma jet rig. This work was 13 supported by the Engineering and Physical Sciences Research Council (EPSRC) grant 14 reference: EP/G048444/1. 


\section{Figure captions}

2

3 FIG. 1 (a) showing schematic of the experimental setup, the HPR-60 molecular beam 4 mass spectrometer with an atmospheric pressure micro-plasma jet on the $x$-y stage placed in front of the $100 \mu \mathrm{m}$ orifice. P1, P2, and P3 are pressure reduction stages. (b) shows a schematic of voltage and current measurements.

FIG. 2 Plots of the typical driving voltage (a), current signals, total and discharge currents, (b) and bullet current (c). In this case the driving frequency is $10 \mathrm{kHz}$.

FIG. 3 An image of a plasma jet driven $10 \mathrm{kHz}$ and $8 \mathrm{kV}_{\mathrm{p}-\mathrm{p}}$ ac, and 1.38 slm helium flow taken using an ICCD camera. (a) shows time-averaged plasma plume ( $0.5 \mathrm{~s}$ exposure time) and (b) shows time-averaged plasma bullet (100 ns exposure time and $35.6 \mu$ s delay time).

FIG. 4 A mass spectra plot of positive ions (a) and negative ions (b), measured in the outflow plasma jet at a distance of $7 \mathrm{~mm}$ from the gas nozzle. The jet was operated at 10 $\mathrm{kHz}$ and $8 \mathrm{kV}_{\mathrm{p}-\mathrm{p}}$ ac, with 1.38 slm helium flow.

FIG. 5 The spatial distributions of (a) positive ion flux and (b) negative ion flux along a line between the jet nozzle and the instrument orifice. The same operating conditions at in fig 4.

FIG. 6 The time-resolved positive and negative ion fluxes for selected species measured 1 also shown. 
$1 \quad$ FIG. 7 The time-resolved positive and negative ion fluxes for selected species measured 7

$2 \mathrm{~mm}$ from the nozzle at $5 \mathrm{kHz}$. The associated voltage, discharge and bullet currents are 3 also shown.

4

5 FIG. 8 The time-resolved positive and negative ion fluxes for selected species measured

$611 \mathrm{~mm}$ from the nozzle at $5 \mathrm{kHz}$. The associated voltage, discharge and bullet currents are $7 \quad$ also shown.

8

9 FIG. 9 The time-resolved positive and negative ion fluxes for selected species measured 7 $10 \mathrm{~mm}$ from the nozzle at $10 \mathrm{kHz}$. The associated voltage, discharge and bullet currents are 11 also shown.

12

13 FIG. 10 The time-resolved positive and negative ion fluxes for selected species measured $147 \mathrm{~mm}$ from the nozzle at $25 \mathrm{kHz}$. The associated voltage, discharge and bullet currents are 15 also shown.

16 
1 Table 1 The positive and negative species detected in the plasma plume with their relative 2 abundance by atomic percentage.

\begin{tabular}{|c|c|c|c|}
\hline \multirow{2}{*}{ amu } & \multirow{2}{*}{$\begin{array}{c}\begin{array}{c}\text { Standard } \\
\text { atmosphere }\end{array} \\
\text { Neutrals }\end{array}$} & \multicolumn{2}{|c|}{ Micro-plasma jet and ambient air } \\
\hline & & Positive ions & Negative ions \\
\hline 4 & & $\mathrm{He}^{+}(1.79)$ & \\
\hline 14 & & $\mathrm{~N}^{+}(2.38)$ & \\
\hline 16 & & $\mathrm{O}^{+}(2.48)$ & $\mathrm{O}^{-}(1.89)$ \\
\hline 17 & & & $\mathrm{OH}^{-}(0.76)$ \\
\hline 18 & $\mathrm{H}_{2} \mathrm{O}(0.4)$ & $\mathrm{H}_{2} \mathrm{O}^{+}(0.37)$ & \\
\hline 28 & $\mathrm{~N}_{2}(78.08)$ & $\mathrm{N}_{2}^{+}(65.26)$ & \\
\hline 29 & & $\mathrm{~N}_{2} \mathrm{H}^{+}(1.38)$ & \\
\hline 30 & & $\mathrm{NO}^{+}(3.76)$ & \\
\hline 32 & $\mathrm{O}_{2}(20.94)$ & $\mathrm{O}_{2}^{+}(21.11)$ & $\mathrm{O}_{2}^{-}(5.43)$ \\
\hline 33 & & $(\mathrm{OH}) \mathrm{O}^{+}(0.15)$ & $(\mathrm{OH}) \mathrm{O}^{-}(2.68)$ \\
\hline 34 & & $\mathrm{O}\left(\mathrm{H}_{2} \mathrm{O}\right)^{+}(0.12)$ & $\mathrm{O}^{-}\left(\mathrm{H}_{2} \mathrm{O}\right)(1.19)$ \\
\hline 35 & & & $\mathrm{OH}^{-}\left(\mathrm{H}_{2} \mathrm{O}\right)(5.79)$ \\
\hline 40 & $\operatorname{Ar}(0.9337)$ & $\mathrm{Ar}^{+}(0.56)$ & \\
\hline 44 & $\mathrm{CO}_{2}^{-}(0.039)$ & & \\
\hline 46 & & & $\mathrm{NO}_{2}^{-}(0.79)$ \\
\hline 48 & & & $\mathrm{O}_{3}^{-}(22.68)$ \\
\hline 50 & & & $\mathrm{O}_{2}^{-}\left(\mathrm{H}_{2} \mathrm{O}\right)(10.49)$ \\
\hline 51 & & & $(\mathrm{OH}) \mathrm{O}^{-}\left(\mathrm{H}_{2} \mathrm{O}\right)(3.80)$ \\
\hline 52 & & & $\mathrm{O}^{-}\left(\mathrm{H}_{2} \mathrm{O}\right)_{2}(0.46)$ \\
\hline 53 & & & $\mathrm{OH}^{-}\left(\mathrm{H}_{2} \mathrm{O}\right)_{2}(8.19)$ \\
\hline 60 & & & $\mathrm{CO}_{3}^{-}(3.60)$ \\
\hline 61 & & & $\mathrm{HCO}_{3}^{-}(3.25)$ \\
\hline 62 & & & $\mathrm{NO}_{3}^{-}(0.36)$ \\
\hline 65 & & & $\mathrm{O}_{3}(\mathrm{OH})^{-}(2.18)$ \\
\hline 66 & & & $\mathrm{O}_{3}^{-}\left(\mathrm{H}_{2} \mathrm{O}\right)(6.44)$ \\
\hline 67 & & & $\mathrm{O}(\mathrm{OH})_{3}^{-}(0.34)$ \\
\hline 68 & & & $\mathrm{O}_{2}^{-}\left(\mathrm{H}_{2} \mathrm{O}\right)_{2}(1.78)$ \\
\hline 69 & & & $(\mathrm{OH}) \mathrm{O}^{-}\left(\mathrm{H}_{2} \mathrm{O}\right)_{2}(1.46)$ \\
\hline 71 & & & $\mathrm{OH}^{-}\left(\mathrm{H}_{2} \mathrm{O}\right)_{3}(2.08)$ \\
\hline 76 & & & $\mathrm{O}\left(\mathrm{CO}_{3}\right)^{-}(0.20)$ \\
\hline 77 & & & $\mathrm{OH}\left(\mathrm{CO}_{3}\right)^{-}(3.77)$ \\
\hline 78 & & & $\mathrm{CO}_{3}^{-}\left(\mathrm{H}_{2} \mathrm{O}\right)(0.27)$ \\
\hline 79 & & & $\mathrm{HCO}_{3}^{-}\left(\mathrm{H}_{2} \mathrm{O}\right)(1.41)$ \\
\hline 82 & & & $\mathrm{NO}_{2}^{-}\left(\mathrm{H}_{2} \mathrm{O}\right)_{2}(0.30)$ \\
\hline 84 & $\operatorname{Kr}(0.65 \mathrm{E}-4)$ & & $\mathrm{O}_{3}{ }^{-}\left(\mathrm{H}_{2} \mathrm{O}\right)_{2}(0.96)$ \\
\hline 86 & & & $\mathrm{O}_{2}^{-}\left(\mathrm{H}_{2} \mathrm{O}\right)_{3}(0.27)$ \\
\hline 87 & & & $(\mathrm{OH}) \mathrm{O}^{-}\left(\mathrm{H}_{2} \mathrm{O}\right)_{3}(0.85)$ \\
\hline 89 & & & $\mathrm{OH}^{-}\left(\mathrm{H}_{2} \mathrm{O}\right)_{4}(1.25)$ \\
\hline 94 & & & $\mathrm{NO}_{5}^{-}(1.36)$ \\
\hline 95 & & & $(\mathrm{OH}) \mathrm{CO}_{3}{ }^{-}\left(\mathrm{H}_{2} \mathrm{O}\right)(1.42)$ \\
\hline 96 & & & $\mathrm{CO}_{3}{ }^{-}\left(\mathrm{H}_{2} \mathrm{O}\right)_{2}(0.23)$ \\
\hline 97 & & & $\mathrm{HCO}_{3}{ }^{-}\left(\mathrm{H}_{2} \mathrm{O}\right)_{2}(0.89)$ \\
\hline
\end{tabular}




\section{References}

[1] Liston E M, Martinu L and Wertheimer M R 1994 Plasma surface modification of polymers: relevance to adhesion $V S P B V$ Chapter 1

[2] Tachibana K 2006 Current status of microplasma research IEEJ Trans. 1 145-155

[3] Koinuma H, Ohkubo H, Hashimoto T, Inomata Kiyoto, Shiraishi T, Miyanaga A, Hayashi S 1991 Development and application of a microbeam plasma generator Applied Physics Letter, 60816

[4] Jeong J Y, Babayan S E, Tu V J, Park J, Henins I, Hicks R F and Selwyn G S 1998 Etching materials with an atmospheric-pressure plasma jet Plasma Sources Sci. Technol. 7282

[5] Ito Y, Urabe K, Takano N, Tachibana K 2008 High speed deposition of $\mathrm{SiO}_{2}$ films with plasma jet based on capillary dielectric barrier discharge at atmospheric pressure Appl. Phys. Express, 1 067009-3

[6] Szili E J, Al-Baraineh A S, Bryant P M, Short R D, Bradley J W, and Steele D A 2011 Controlling the spatial distribution of polymer surface treatment using atmosphericpressure microplasma jets Plasma Process. Polym. 838

[7] Lee K, Paek K-H, Ju W-T and Lee Y 2006 Sterilization of bacteria, yeast, and bacterial endospores by atmospheric-pressure cold plasma using helium and oxygen Journal of Microbiology 44 269-275

[8] Fridman G, Friedman G, Gutsol A, Shekhter A B, Vasilets V N and Fridman A 2008 Applied plasma medicine Plasma Process. Polym. 5 503-533

[9] Price R O, Chiavanini R, Kolb J F and Schoanbach K H 2009 Cold air atmospheric pressure micro plasma jet application method and device United States Patent US2009/0121638A1

[10] Stoffels E, Flikweert A J, Stoffels W W and Krosesn G M W 2002 Plasma needle: a non-destructive atmospheric plasma source for fine surface treatment of (bio)materials Plasma Sources Sci. Technol. 11383 
[11] Kakei R, Ogino A, Iwata F and Nagatsu M 2010 Production of Ultrafine Atmospheric Pressure Plasma Jet with Nano-capillary Thin Solid Films 5183457

[12] Urabe K, Morita T, Tachibana K and Ganguly B N 2010 Investigation of discharge mechanisms in helium plasma jet at atmospheric pressure by laser spectroscopic measurements J. Phys. D: Appl. Phys. 43095201

[13] Walsh J L, Shi J J and Kong M G 2006 Contrasting characteristics of pulsed and sinusoidal cold atmospheric plasma jets Appl. Phys. Lett. 88171501

[14] Bruggeman P, Iza F, Guns, Lauwers D, Kong M G, Aranda Gonzalvo Y, Leys C and Schram D C 2010 Electronic quenching of $\mathrm{OH}(\mathrm{A})$ by water in atmospheric pressure plasmas and its influence on the gas temperature determination by $\mathrm{OH}(\mathrm{A}-\mathrm{X})$ emission Plasma Sources Sci. Technol. 19015016

[15] Qian M, Ren C, Wang D, Zhang J and Wei G 2010 Stark broadening measurement of the electron density in an atmospheric pressure argon plasma jet with double-power electrodes J. Appl. Phys. 107063303

[16] Teschke M, Kedzierski J, Finantu-Dinu E G, Korzec D and Engemann J 2005 Highspeed photographs of a dielectric barrier atmospheric pressure plasma jet IEEE Tran. on Plasma Sci. 33310

[17] Mazouffre S, Bakker I, Vankan P, Engeln R and Schram D C 2002 Tow-photon laser induced fluorescence spectroscopy performed on free nitrogen plasma jets Plasma Sources Sci. Technol. 11439

[18] Oh J-S, Olabanji O T, Hale C, Mariani R, Kontis K and Bradley J W 2011 Imaging gas and plasma interaction in the surface chemical modification of polymers by micro-plasma jet J. Phys. D: Appl. Phys. 44155206

[19] Skalny J D, Orszagh J, Mason N J Rees J A, Aranda-Gonzalvo Y and Whitmore T D 2008 Mass spectrometric study of negative ions extracted from point to plane negative corona discharge in ambient air at atmospheric pressure Intl. J. Mass Spectromerty 27212 
[20] Malović G, Puač N, Laszović S and Petrović Z 2010 Mass analysis of an atmospheric pressure plasma needle discharge Plasma Sources Sci. Technol. 19034014

[21] Stoffels E, Aranda-Gonzalvo Y, Whitmore T D, Seymour D L and Rees J A 2007 Mass spectrometric detection of short-living radicals produced by a plasma needle Plasma Sources Sci. Technol. 16549

[22] Rees J A, Seymour D L, Greenwood C-L, Aranda-Gonzalvo Y and Lundie D T 2008 Mass and energy spectrometry of atmospheric pressure plasmas Plasma Process. Polym. 7 92

[23] Waskoenig J, Niemi K, Knake N, Graham L M, Reuter S, Schulz-von der Gathen V and Gans T 2010 Atomic oxygen formation in a radio-frequency driven micro-atmospheric pressure plasma jet Plasma Sources Sci. Technol. 19045018

[24] Bruggeman P, Iza F, Lauwers D and Aranda-Gonzalvo Y 2010 Mass spectrometry study of positive and negative ions in a capacitively coupled atmospheric pressure RF excited glow discharge in He-water mixtures J. Phys. D: Appl. Phys. 43012003

[25] Probe transit time http://www.hidenanalytical.com/

[26] Oh J-S, Bryant P M and Bradley J W 2010 Discharge and Plasma Bullet Formation in a Capillary DBD Atmospheric Pressure Micro-plasma Jet IEEE Tran. on Plasma Sci. in press.

[27] Pouvesle J M, Bouchoule A and Stevefelt J 1982 Modelling of the charge transfer afterglow by intense electrical discharges in high pressure helium nitrogen mixtures $J$. Chem. Phys. 77817

[28] Martens T, Bogaerts A, Brok W J M and Dijk J V 2008 The dominant role of impurities in the composition of high pressure noble gas plasmas Appl. Phys. Lett. 92041504

[29] Stafford D S and Kushner M J $2004 \mathrm{O}_{2}\left({ }^{1} \Delta\right)$ production in $\mathrm{He} / \mathrm{O}_{2}$ mixtures in flowing low pressure plasmas J. Appl. Phys. 962451

[30] Itikawa Y 2009 Cross sections for electron collisions with oxygen molecules J. Phys. Chem. Ref. Data 381 
[31] Itikawa Y and Mason N 2005 Cross sections for electron collisions with water molecules J. Phys. Chem. Ref. Data 341

[32] Karakas E, Koklu M and Laroussi M 2010 Correlation between helium mole fraction and plasma bullet propagation in low temperature plasma jets J. Phys. D: Appl. Phys. $\mathbf{4 3}$ 155202

[33] Sekimoto K and Takayama M 2010 Negative ion formation and evolution in atmospheric pressure corona discharges between point-to-plane electrodes with arbitrary needle angle Eur. Phys. J. D 60 589-599

[34] Walsh J L and Kong M G 2008 Frequency effects of plasma bullets in atmospheric glow discharges IEEE Trans. on Pleasma Sci. 36954

[35] Sands B L, Ganguly B N and Tachibana K 2008 A streamer-like atmospheric pressure plasma jet Appl. Phys. Lett. 92151503

[36] Laroussi M, Hynes W, Akan T, Lu X and Tendero C 2008 The plasma pencil: a source of hypersonic cold plasma bullets for biomedical applications IEEE Trans. on Pleasma Sci. 361298

[37] Cao Z, Walsh J L and Kong M G 2009 Atmospheric plasma jet array in parallel electric and gas flow fields for three-dimensional surface treatment Appl. Phys. Lett. 94021501

[38] Sabo M, Páleník J, Kučera M, Han H, Wang H, Chu Y and Matejčík S 2010 Atmospheric pressure corona discharge ionisation and ion mobility spectrometry/mass spectrometry study of the negative corona discharge in high purity oxygen and oxygen/nitrogen mixtures Intl. J. Mass Spectrometry 293 23-27, 


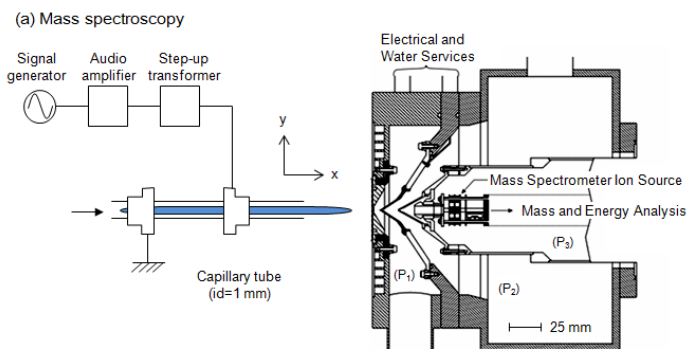

(b) Voltage and current measurements

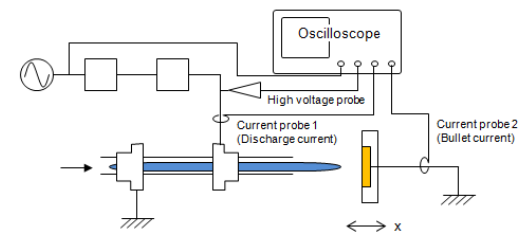

Figure 1 (Fig 1 R1.bmp) 


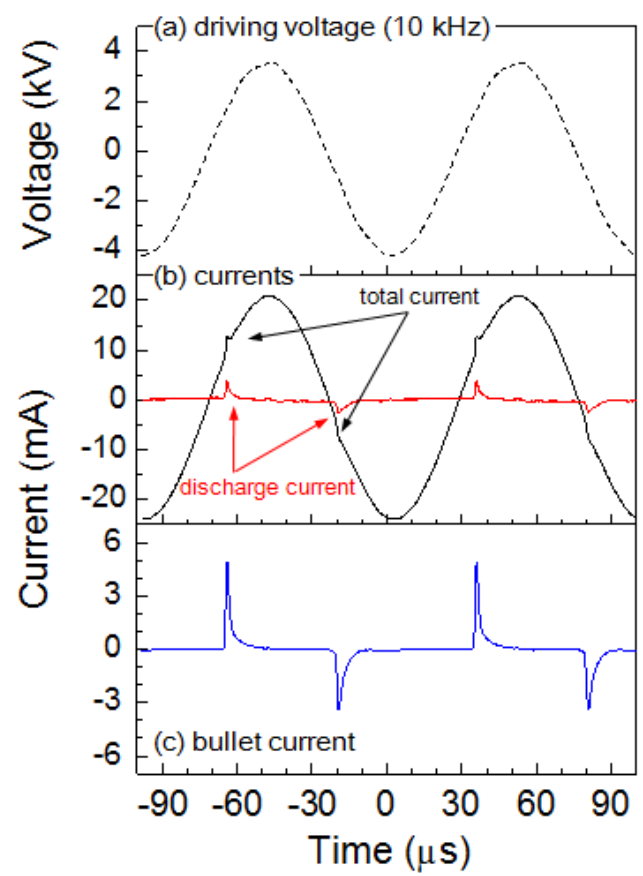

Figure 2 (Fig 2 R1.bmp) 


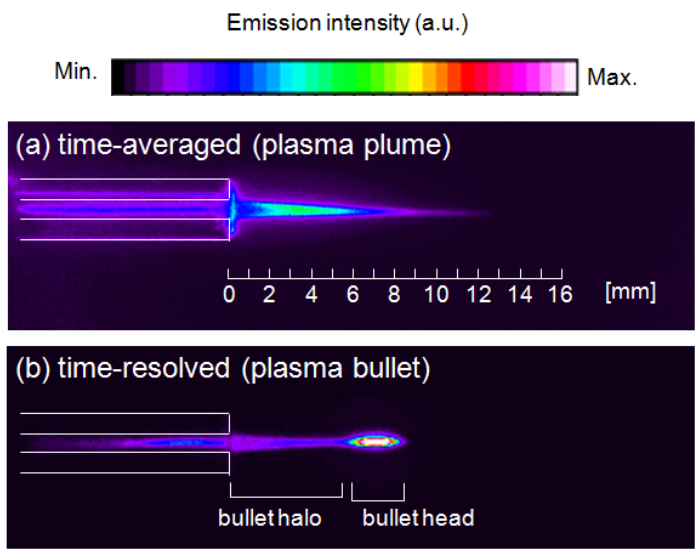

Figure 3 (Fig 3 R1.bmp) 


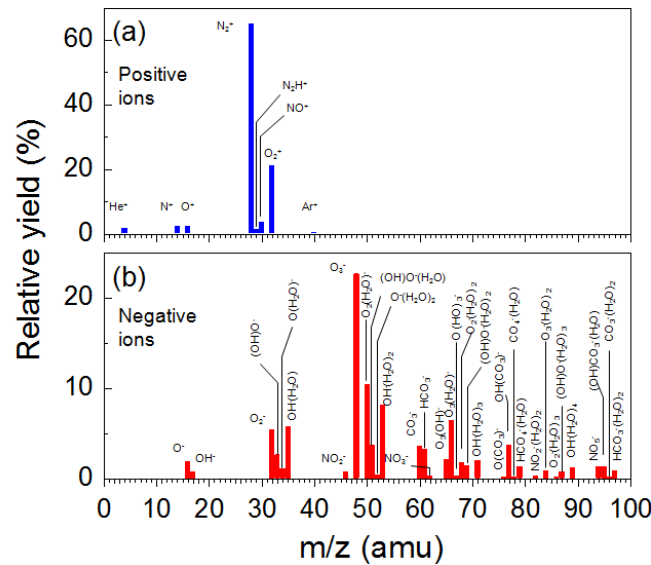

Figure 4 (Fig 4 R1.bmp) 


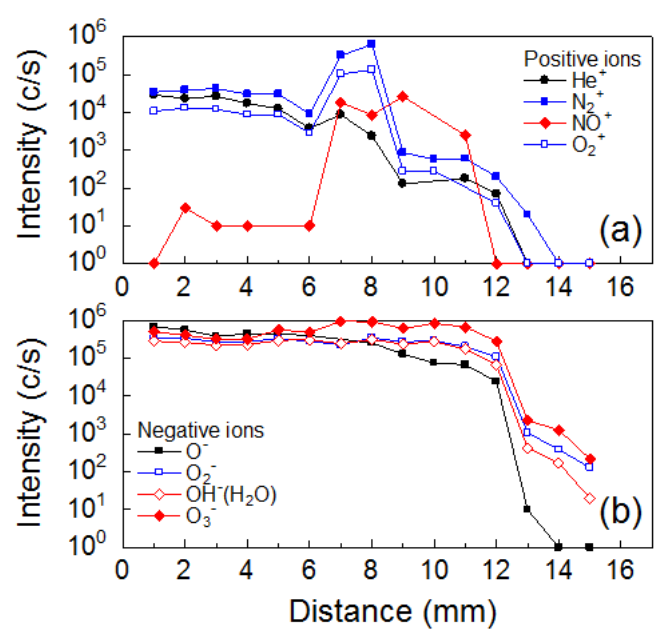

Figure 5 (Fig 5 R1.bmp) 

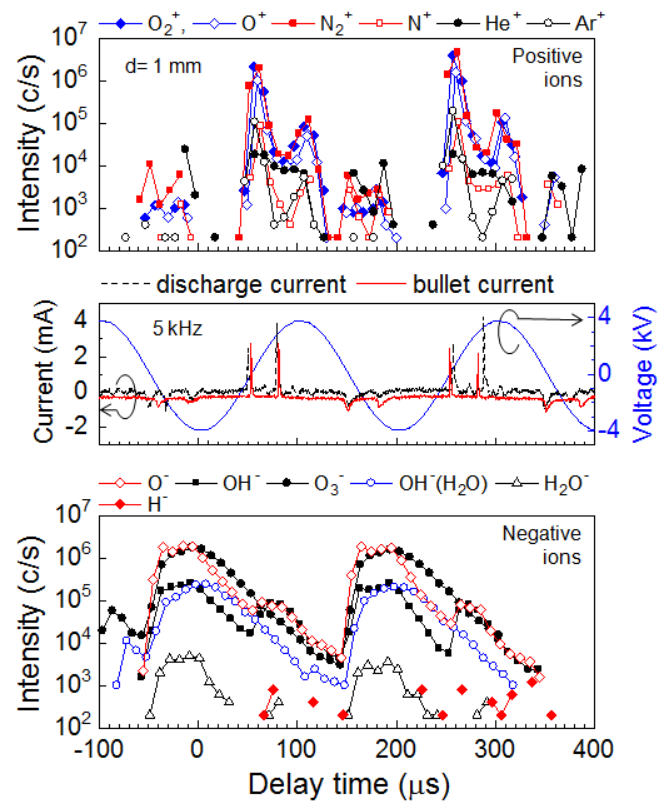

Figure 6 (Fig 6 R1.bmp) 

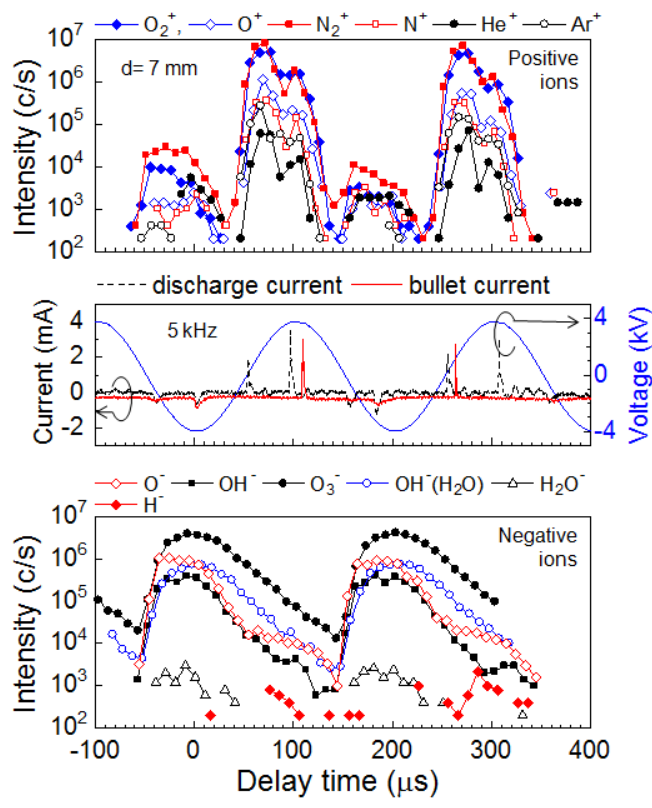

Figure 7 (Fig 7 R1.bmp) 

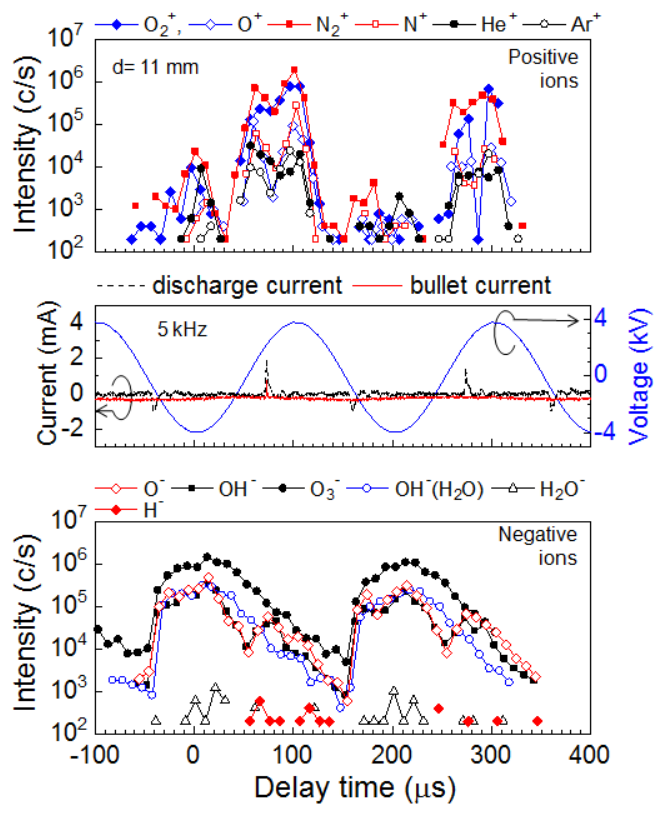

Figure 8 (Fig 8 R1.bmp) 

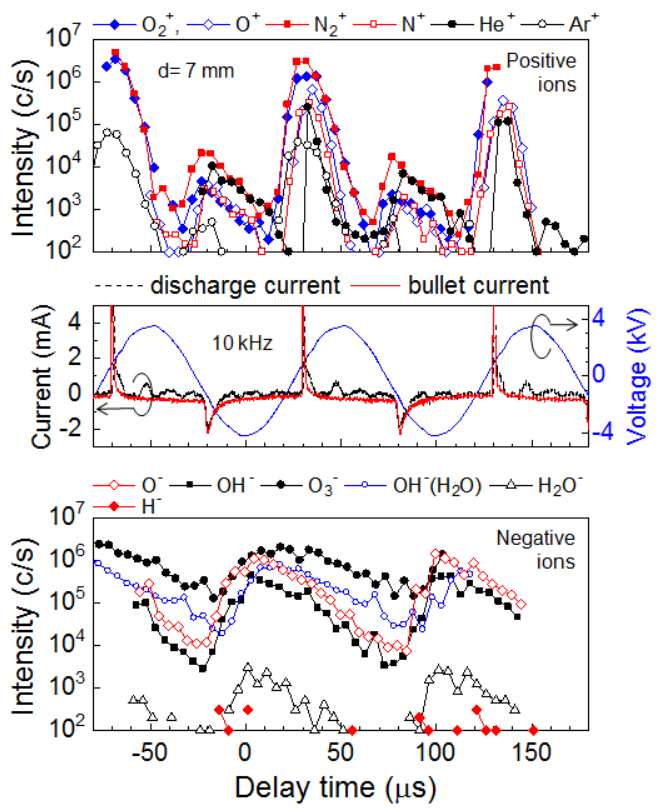

Figure 9 (Fig 9 R1.bmp) 

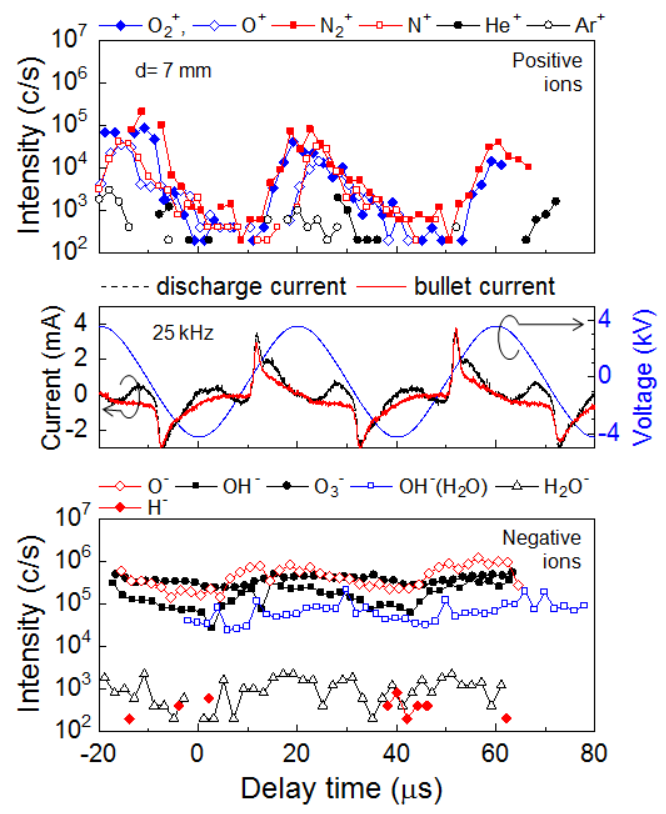

Figure 10 (Fig 10 R1.bmp) 